This item was submitted to Loughborough's Research Repository by the author.

Items in Figshare are protected by copyright, with all rights reserved, unless otherwise indicated.

\title{
Optical switching of 1-D microstrip photonic bandgap structures
}

PLEASE CITE THE PUBLISHED VERSION

http://dx.doi.org/10.1109/ICMMT.2002.1187868

\section{PUBLISHER}

(c) IEEE

\section{VERSION}

AM (Accepted Manuscript)

\section{PUBLISHER STATEMENT}

This work is made available according to the conditions of the Creative Commons Attribution-NonCommercialNoDerivatives 4.0 International (CC BY-NC-ND 4.0) licence. Full details of this licence are available at: https://creativecommons.org/licenses/by-nc-nd/4.0/

\section{LICENCE}

CC BY-NC-ND 4.0

\section{REPOSITORY RECORD}

Cadman, Darren A., Robert E. Miles, Robert W. Kelsall, and David Hayes. 2019. "Optical Switching of 1-D Microstrip Photonic Bandgap Structures". figshare. https://hdl.handle.net/2134/26446. 


\title{
Optical Switching of 1-D Microstrip Photonic Bandgap Structures
}

\author{
Darren Cadman, Robert Miles, Robert Kelsall and David Hayes
}

\begin{abstract}
The optical control of a microstrip one dimensional (1-D) photonic bandgap (PBG) structure has been demonstrated over the frequency range 7-13GHz. A microstrip PBG structure was fabricated on Duroid 6010 and a high resistivity photoconductive $\mathrm{Si}$ wafer was placed in contact with the ground plane. With no optical illumination incident upon the $\mathrm{Si}$, the microstrip PBG filtering properties are well-defined. When the $\mathrm{Si}$ is illuminated the filtering properties are suppressed. Under illumination the experimental results display an increase in $S_{21}$ of $6.5 \mathrm{~dB}$ and a reduction in $S_{11}$ of more than $8 \mathrm{~dB}$ at the centre frequency of 10GHz. Experimental results are presented alongside those simulated.
\end{abstract}

Keywords - Microstrip, optical control, periodic structures, photonic bandgap (PBG), photoconductivity, plasma, silicon.

\section{INTRODUCTION}

$\mathrm{T}$ HE concept of a Photonic Bandgap (PBG) structure for microstrip technology was first introduced and realized by Qian et al. in 1997 [1]. Previous to that, research on PBGs had been primarily focused in the optical regime [2]. The microstrip PBG structure in [1] consists of holes drilled through the microstrip substrate to form a periodically spaced honeycomb lattice. The fabrication of microstrip PBGs was made easier with the realization that they could be fabricated by etching holes in the ground plane thus removing the need to drill holes through the substrate. An added advantage of this fabrication method is improved stopband characteristics in terms of depth and width [3]. There has been much research into the topic of microstrip PBGs with regard to, for example, different hole patterns and shapes and their associated filtering properties [4][5] and ap-

Darren Cadman, Robert Miles and Robert Kelsall are with the Institute of Microwaves and Photonics, School of Electronic and Electrical Engineering, University of Leeds, Leeds, LS2 9JT, UK. E-mail: d.a.cadman@ieee.org .

David Hayes is with ESL Defence Ltd. and Plasma Antennas Ltd., 2-4 Compass Point, Ensign Way, Hamble, Southampton, SO31 4RA, UK. E-mail: dh@plasmaantennas.com plications, such as the suppression of harmonic frequencies [6][7].

To date the optical control of microstrip PBGs has not been reported. However the optical control of microwave circuits has been reported previously and the frequency of published articles has increased over the past 5 years. Applications include the optical switching of frequency selective surfaces [8][9], optically controlled steerable microwave antennas [10] and the optical control of co-planar waveguide Bragg gratings [11]. Each of these applications exploit the change in a semiconductor's conductivity when it is irradiated with photons of energy greater than its bandgap energy.

In this paper, simulated and experimental results are presented for a microstrip 1-D PBG structure with optical control.

\section{Plasma in Semiconductor Material}

An unilluminated semiconductor can be regarded as a dielectric material especially if it is of a high purity. Under illumination electron-hole pairs are generated forming a conducting plasma that at sufficiently high excess carrier densities can appear to be metallic to an electromagnetic wave. The generation of electron-hole pairs modifies the relative permittivity of the $\mathrm{Si}$, as described by [12]:

$$
\epsilon_{r}=\epsilon_{L} \epsilon_{0}-\sum_{i=e, h} \frac{\omega_{p}^{2}}{\omega^{2}+\left(\frac{1}{\tau_{i}}\right)^{2}}\left(1+j \frac{1}{\omega \tau_{i}}\right)
$$

where $\epsilon_{L}$ is the dielectric constant of the host lattice (11.9 for $\mathrm{Si}), \epsilon_{0}$ is the permittivity of free space, $\omega$ is the radial frequency, $\tau_{i}$ is the mean time between collisions for the carriers and $\omega_{p}$ is the plasma frequency as given by:

$$
\omega_{p}=\sqrt{\frac{n q^{2}}{\epsilon_{0} m_{i}^{*}}}
$$

in which $n$ is the plasma density, $q$ is the electronic charge and $m_{i}^{*}$ is the effective mass of the 
carrier. At high levels of generation the mean time between collisions decreases as more coulomb interactions occur. As a result the mobility of the carriers decreases [13]. Fig 1 shows that at low excess carrier densities the real part of the permittivity dominates and the $\mathrm{Si}$ is in its dielectric regime. At high levels of excess carrier density the imaginary part is dominant and the Si acts as a conductor. The photogenerated conductivity, $\hat{\sigma}$,

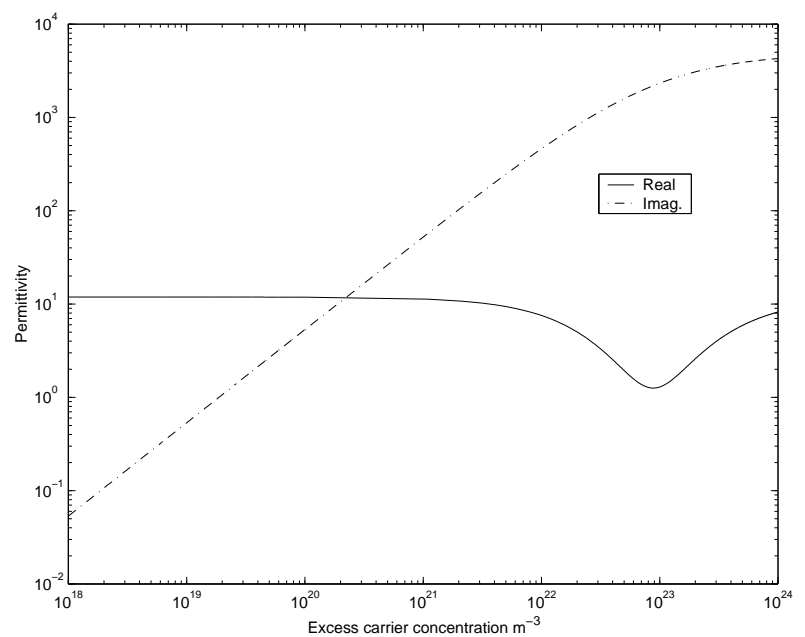

Fig. 1. Variation of permittivity with excess carrier density for $\mathrm{Si}$ at $10 \mathrm{GHz}$

of the $\mathrm{Si}$ is plotted against excess carrier density in Fig. 2 for high excess carrier densities and was calculated using:

$$
\hat{\sigma}=q \hat{n}\left(\mu_{e}(\hat{n})+\mu_{h}(\hat{n})\right)
$$

where $\hat{n}$ is the excess carrier density and, $\mu_{e}$ and $\mu_{h}$ are the excess carrier dependent mobilities as given by [13].

\section{PBG DESIGN}

The microstrip PBG structure illustrated in Fig. 3 was designed for operation over a frequency range of $7-13 \mathrm{GHz}$ with a centre stopband frequency $f_{c}=10 \mathrm{GHz}$. It was fabricated on RT/Duroid $6010\left(\epsilon_{r}=10.2\right)$ with a single row of 6 circular holes etched in the ground plane directly under the microstrip line. The holes were equally spaced a distance $a$ apart where $a=\lambda_{g} / 2$ and $\lambda_{g}$ is the guided wavelength at $f_{c}$. The hole radius $r$ was $r=0.3 a$. The microstrip line width was calculated using conventional microstrip design equations to give a line impedance of $50 \Omega$ at 10GHz. A high resistivity $\left(\rho_{S i}=60 \Omega \mathrm{m}^{-1}\right) \mathrm{FZ}$

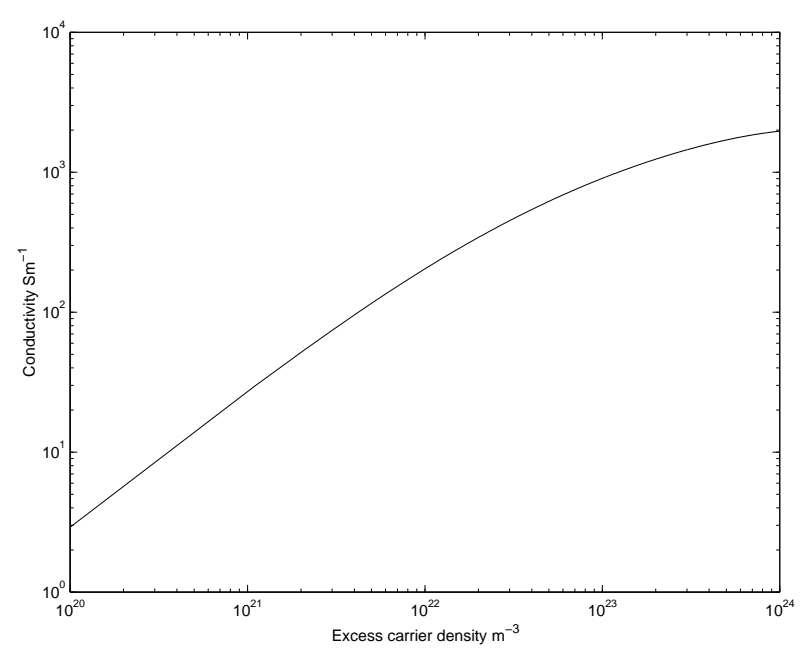

Fig. 2. Si conductivity versus excess carrier density accounting for Coulomb interactions at high injection levels

n-type Si slice was placed beneath and in contact with the microstrip PBG ground plane. The Si was $400 \mu \mathrm{m}$ thick and its effective carrier lifetime was $1-10 \mathrm{~ms}$.

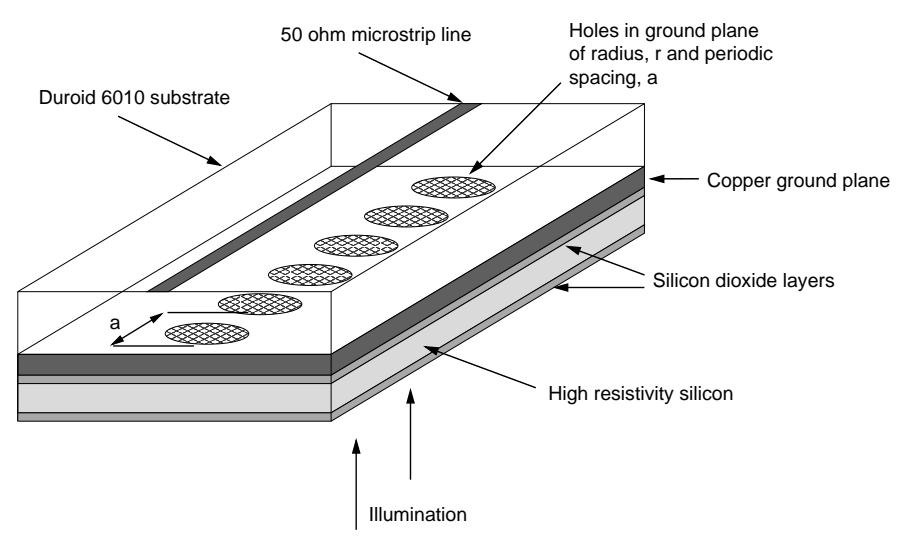

Fig. 3. Microstrip 1-D PBG with photoconducting ground plane

\section{Simulated Results}

Using Agilent HFSS, the structure in Fig. 3 was simulated for a range of values of Si conductivity that represented varying degrees of optical illumination and excess carrier density. In each case the photogenerated plasma was assumed to be uniform throughout the Si. In Figs. 4 and 5 simulated S-parameter results are plotted for several values of Si conductivity. In the simulations the unilluminated case was represented by a Si conductivity $\sigma_{S i}=16 \mathrm{mSm}^{-1}$. To represent varying degrees of optical illumination Si conductivity values of 10 , 50 , and $500 \mathrm{Sm}^{-1}$ are plotted; the higher the value 
for $\sigma_{S i}$, the higher the level of illumination. Fig. 4 shows that as $\sigma_{S i}$ increases the magnitude of the reflection coefficient decreases. From Fig. 5 it can be seen that for $\sigma_{S i} \geq 50 \mathrm{Sm}^{-1}$ the magnitude of the transmission coefficient improves at $f_{c}$ with increasing $\sigma_{S i}$. At high Si conductivities the bandstop filtering properties are suppressed and the $\mathrm{Si}$ acts as a complete conducting ground plane. Fig.

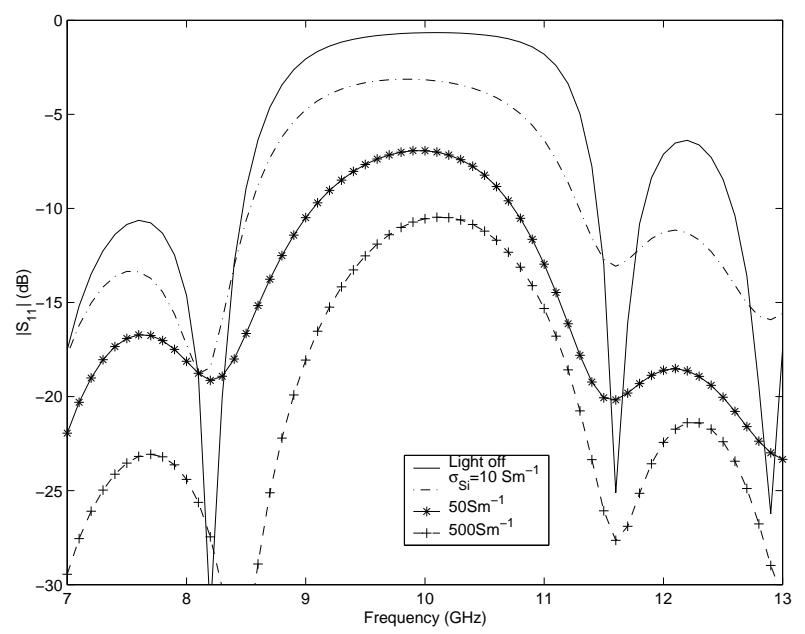

Fig. 4. Simulated $\mathrm{S}_{11}$ of $1-\mathrm{D}$ microstrip PBG for several values of Si conductivity

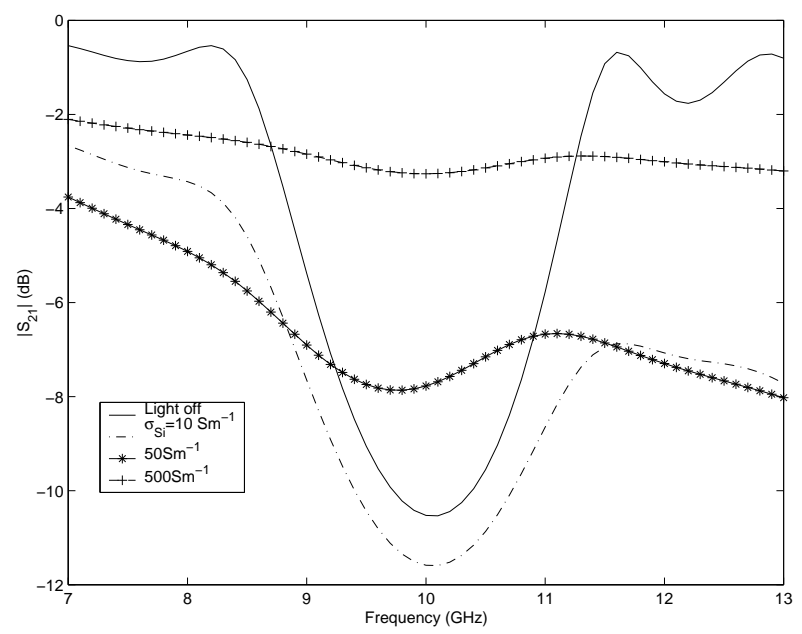

Fig. 5. Simulated $\mathrm{S}_{21}$ of $1-\mathrm{D}$ microstrip PBG for several values of Si conductivity

6 displays how the loss of the structure varies with $\mathrm{Si}$ conductivity at $10 \mathrm{GHz}$. The loss of the structure was calculated from:

$$
\text { Loss }=1-\left(\left|S_{11}\right|^{2}+\left|S_{21}\right|^{2}\right)
$$

It can be seen that the loss is at a maximum when the conductivity of the $\mathrm{Si}$ is $30-50 \mathrm{Sm}^{-1}$. At conductivities less than this the filtering properties of the PBG are still visible. However at values of $\sigma_{S i}>50 \mathrm{Sm}^{-1}$ the loss decreases with increasing $\sigma_{S i}$ and the structure starts to behave more like a conventional microstrip line.

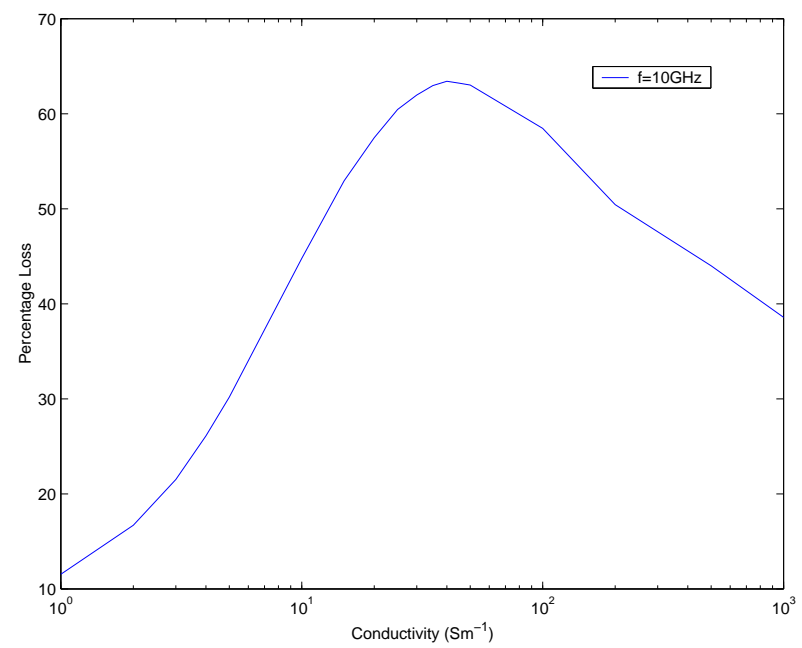

Fig. 6. Loss of optically controlled 1-D microstrip PBG calculated for a range of Si conductivities at $f_{c}=10 \mathrm{GHz}$

\section{EXPERIMENTAL RESUlts}

The experimental results in Figs. 7 and 8 show that in the dark, the microstrip PBG acts as a bandstop filter with a $3 \mathrm{~dB}$ bandwidth of $2.5 \mathrm{GHz}$ and stopband depth of $-12 \mathrm{~dB}$ at $10 \mathrm{GHz}$. These results are in good agreement with the simulated. When the $\mathrm{Si}$ is optically excited by light from a halogen bulb, the conducting plasma formed within the Si suppresses the bandstop characteristics. An increase in the transmission coefficient of $6.5 \mathrm{~dB}$ and a decrease of $8 \mathrm{~dB}$ in reflection coefficient are observed at $10 \mathrm{GHz}$. Comparison of simulated results with experimental show that the photogenerated conductivity is $100-200 \mathrm{Sm}^{-1}$ which from Fig. 2 corresponds to an excess carrier density in the range $4 \times 10^{21} \mathrm{~m}^{-3}<\hat{n}<10^{22} \mathrm{~m}^{-3}$.

\section{Conclusions}

The optical control of a microstrip 1-D PBG circuit has been demonstrated. Initial experimental results suggest that a $\mathrm{Si}$ conductivity in the range 100-200 $\mathrm{Sm}^{-1}$ has been achieved. With a higher excess carrier density it is expected that the bandstop characteristics can be suppressed further and a reduction in the loss of the circuit will result. 


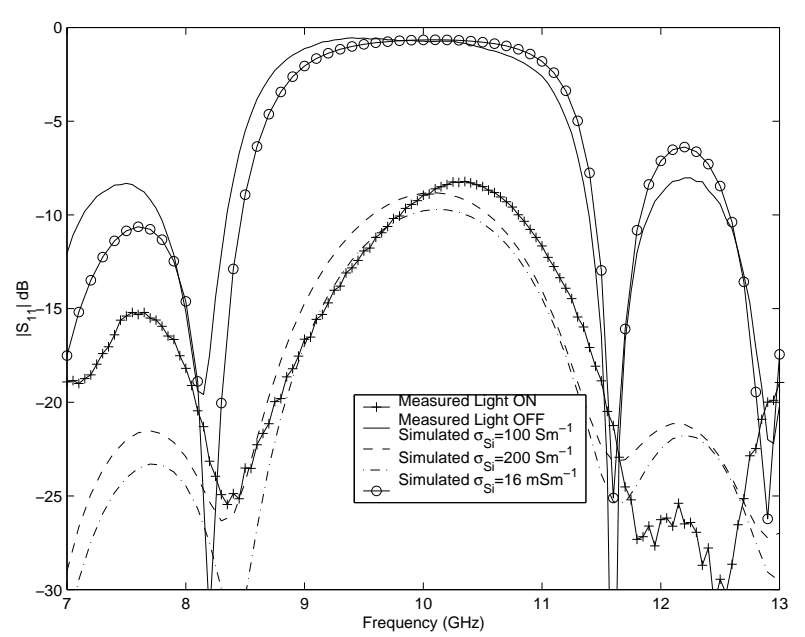

Fig. 7. $\mathrm{S}_{11}$ experimental results of optically controlled microstrip 1-D PBG compared with simulated results

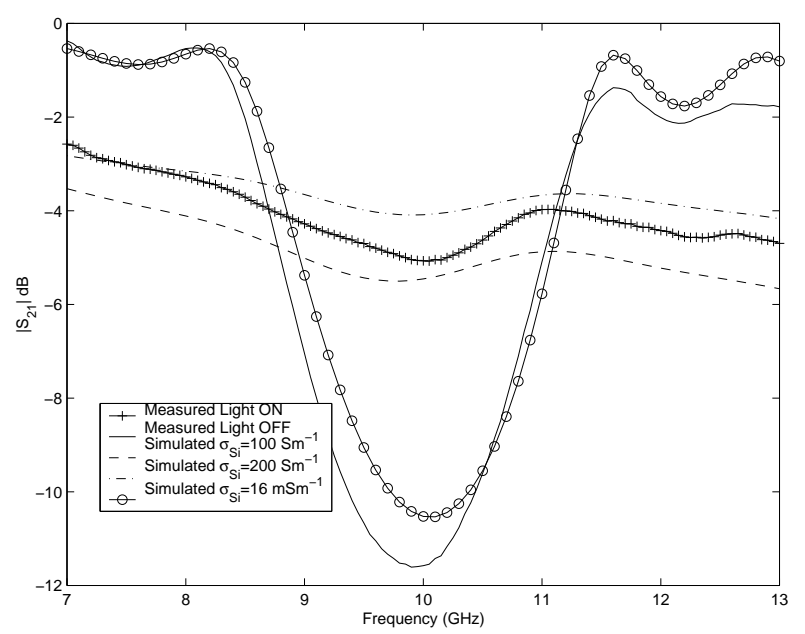

Fig. 8. $\mathrm{S}_{21}$ experimental results of optically controlled microstrip 1-D PBG compared with simulated results

\section{ACKNOWLEDGMENTS}

This work was funded by the Engineering and Physical Science Research Council, ESL Defence Limited and Plasma Antennas Limited.

\section{REFERENCES}

[1] Y. Qian, V. Radisic and T. Itoh, "Simulation and experiment of Photonic Bandgap Structures for microstrip circuits," APMC'97 Proc., Hong Kong, pp. 585-588, Dec. 1997.

[2] E. Yablonovitch, "Inhibited spontaneous emission in solidstate physics and electronics," Phys. Rev. Lett., vol.58, no. 20, pp. 2059-2062, May 1987.

[3] V. Radisic, Y. Qian, R. Coccioli and T. Itoh, "Novel 2D Photonic Bandgap structure for microstrip lines," IEEE Microwave Guided Wave Lett., vol. 8, no.2, pp. 69-71, Feb. 1998.

[4] M. A. G. Laso, T. Lopetegi, M. J. Erro, D. Benito, M. J. Garde, and M. Sorolla, "Multiple frequency tuned Photonic Bandgap microstrip structures," IEEE Microwave Guided Wave Lett., vol. 10, no.6, pp. 220-222, Jun. 2000.

[5] F. Falcone, T. Lopetegi and M. Sorolla. "1-D and 2-D Pho- tonic Bandgap Microstrip structures," Microwave and $O p$ tical Tech. Lett., vol. 22, no.6, pp. 411-412, Sept. 1999.

[6] Y. Horii and M. Tsutsumi "Harmonic control by Photonic Bandgap on microstrip patch antenna," IEEE Microwave Guided Wave Lett., vol. 9, no.1, pp. 13-15, Jan. 1999.

[7] F. Yang, K. Ma, Y. Qian and T. Itoh, "A uniplanar compact Photonic Bandgap (UC-PBG) structure and its applications for microwave circuits," IEEE Trans. Microwave Theory Tech., vol.47, no. 8, pp. 1509-1514, Aug. 1999.

[8] J. C. Vardaxoglou, "Optical switching of frequency selective surfae bandpass response," Electronics Lett., vol. 32, pp. 2345-2346, Dec. 1996.

[9] Y. W. M. Chia and A. Alphones, "Optically controlled frequency selective surface with semiconductor substrate," IEEE Antennas and Propagation Society International Symposium, no.1, pp. 158-161, 1998.

[10] V. A. Manasson, V. I. Litvinov and L. S. Sadovnik, "Electronically steerable semiconductor-based MMW antennas," Proceedings of SPIE., vol. 4111, pp. 210-220, 2000.

[11] W. Platte, S. Ruppik and M. Guetschow "Optically induced mask-controlled time-variable periodic microwave structures," IEEE Trans. Microwave Theory Tech., vol. 48, no.5, pp. 846-851, May 2000.

[12] C. H. Lee, P. S. Mak and A. P. DeFonzo, "Optical control of millimeter-wave propagation in dielectric waveguides," IEEE Journal of Quantum Electronics, vol. QE-16, pp. 277288, Mar. 1980.

[13] J. M. Dorkel and Ph. Leturcq, "Carrier mobilities in silicon semi-empirically related to temperature, doping and injection level," Solid-state electron., vol. 24, no.9, pp. 821-825, 1981. 